\title{
Editorial \\ The Contribution of Mobile Mental Health Units to Community Psychiatric Care in Greece
}

\author{
Maria Samakouri $^{1, *(1)}$, Olympia Evagorou ${ }^{1}$ and Athena Frangouli-Sakellaropoulou ${ }^{2}$ \\ 1 Department of Psychiatry, Medical School, Democritus University of Thrace, 68100 Alexandroupolis, Greece; \\ oevagoro@med.duth.gr \\ 2 Society of Social Psychiatry P. Sakellaropoulos, Kallithea, 17673 Athens, Greece; ekpsath@otenet.gr \\ * Correspondence: msamakou@med.duth.gr
}

Citation: Samakouri, M.; Evagorou, O.; Frangouli-Sakellaropoulou, A. The Contribution of Mobile Mental Health Units to Community Psychiatric Care in Greece. Psych 2022, 4, 100-104. https://doi.org/ $10.3390 /$ psych 4010009

Received: 16 January 2022

Accepted: 9 February 2022

Published: 12 February 2022

Publisher's Note: MDPI stays neutral with regard to jurisdictional claims in published maps and institutional affiliations.

Copyright: (C) 2022 by the authors. Licensee MDPI, Basel, Switzerland. This article is an open access article distributed under the terms and conditions of the Creative Commons Attribution (CC BY) license (https:// creativecommons.org/licenses/by/ $4.0 /)$.
The implementation of Mobile Mental Health Units (MMHUs) was a decisive step in the psychiatric reform and the development of community psychiatric care in Greece. Their activity, which aimed not only at treating the disease at a biological level but also at taking action for prevention, timely intervention and psychosocial rehabilitation of the patient, undeniably contributed to a more holistic and anthropocentric psychiatric care for mentally ill $[1,2]$.

MMHUs in Greece are low-cost community psychiatric services (CPS), inspired and implemented by pioneers of community psychiatry [1,3], through which community mental health care is provided and mental health is promoted in rural, remote (mountainous, island) and deprived areas, in which access to mental health services (MHS) is difficult $[2,4]$. They are publicly funded services, run by General Hospitals or by non-profit, non-governmental organizations [5,6]. MMHUs consist of a multidisciplinary team (psychiatrist, child and adolescent psychiatrist, psychologist, nurse, social worker, speech and language therapist), and work closely with the local community, primary health system and primary municipal services, such as local authorities, police, local prosecutors and schools. These units provide community-based treatment and prevention services for the whole range of mental disorders to both adults and children and adolescents of their catchment area. Concerning adults, special emphasis is given on patients with severe mental illnesses (SMI), especially psychotic disorders [2,7]. Periodically (usually every fortnight, depending on local needs), MMHUs visit determined sites within their catchment area, providing outpatient and home care. Throughout their activity, they aim to ensure the continuity of care, the prevention of relapse, the reduction of voluntary and involuntary hospitalizations, the psychosocial rehabilitation of patients, the cooperation with patients' families, the assessment of their needs and the provision of practical help [2,5,7]. Raising community awareness through educational and informational initiatives for mental health, in order to eliminate stigma, reduce discrimination and increase social inclusion of people with mental disorders, is also an important part of the activities of an MMHU [1,2,8]. Their role is also educational for undergraduate and postgraduate students, as well as resident doctors (psychiatrists, general practitioners) who, during their rotation, can have an active role as members of an MMHU's multidisciplinary team [5,7].

MMHUs were enacted in 1999, even though their pilot implementation had started much earlier $[1,3,4]$. The first two of them were established almost simultaneously in the early 1980s: one in central Greece, in the mountainous prefecture of Fokis, and the second one in the northeastern part of the country, on the borders with Turkey and Bulgaria, in the prefecture of Evros (Figure 1). These pilot initiatives aimed, on the one hand, to address the problem of insufficient public and private psychiatric services in their catchment rural areas and, on the other hand, to set a model of CPS for other remote parts of the country with similar geographical and socio-demographic features [5,8-10]. It should be noted that in Greece, around the early 1980s, psychiatric care, mainly regarding SMI, was almost 
exclusively custodial (asylum period). The provision of care was based on nine large Public Psychiatric Hospitals (traditional asylums), three in Athens, one in Thessaloniki and five in other areas (two in the mainland and three on the islands), as well as on private psychiatric clinics, also of asylum features [9,11,12]. The so-called "Colony of Psychopaths of Leros", which had become negatively known throughout Europe for the inhuman and appalling living conditions of the patients in it, was one of the nine aforementioned asylums and was still in operation at that time [13-15]. Aside from a few exceptions, CPS were alarmingly absent. At that period, there was an intense concern in the psychiatric community and the Greek society about the need to modernize and humanize mental health care. In this setting, pioneers of psychiatric reform had taken initiatives to establish MHS within the community $[9,16,17]$. In this setting, initially on a pilot basis, Mental Health Centers (MHCs) and Psychiatric Departments in General Hospitals were founded, mainly in large urban centers and some in the province [11,18-20]. Demand for action and funding from the European Union for the development of modern psychiatric services has been a crucial factor for their implementation [21]. The first two MMHUs, which are presented below, have been a paradigm for the development of CPS, towards covering the needs of rural and remote regions.



Figure 1. First two MMHUs of Greece: (A). MMHU of Fokis; (B). MMHU of Evros.

The MMHU in the prefecture of Fokis was founded in 1981, in an area with a complete absence of MHS until then [10,22-24]. Since its foundation, it provided services to both adults and children and adolescents. With regards to adults, it focused mainly on the care of people with SMI, in order to manage acute episodes and psychotic relapses, as well as to ensure the continuity of care. All care services were provided locally in the community setting, outside of a hospital framework. In acute psychiatric cases, the HomeTreatment method (" $\Psi \curlyvee \Sigma \Pi A$ " in Greek, from the acronym of the patient's psychiatric care at his home) was applied, into which the founder of MMHU and his collaborators had long experience from other settings [1,25]. Very few cases of psychotic relapses had to be referred for short-term admission to a Psychiatric Hospital of Athens, as there was no local possibility for inpatient treatment in the prefecture of Fokis, and after which patients returned to the community services provided by the local MMHU. Furthermore, 
the MMHU focused on cooperating with the community and raising community awareness on psychotic disorders in order to manage acute episodes and relapses without the need of hospitalization. The MMHU of Fokis applies the same basic principles in its operation until today. It has developed a vast network of Psychiatric Services around it, without the support of a psychiatric department of a local General Hospital [8].

In the prefecture of Evros, the MMHU was developed in the early 1980s as a community activity of the first Psychiatric Department of a General Hospital in Greece. The latter had been founded only a few years before [3,5,26-28]. This MMHU served the rural population of the prefecture of Evros and initially provided services to adults with both severe and minor mental disorders $[5,28,29]$. Soon afterwards, following a reorientation of its goals, it gave primary importance to the community-based psychiatric care of adults with SMI and developed services for children and adolescents as well $[1,30]$. Nowadays, the MMHU constitutes part of a network of closely collaborating services that include the Psychiatric Department of the University General Hospital of Alexandroupolis, MHCs in urban areas, residential care, as well as hospitals and CPS for children and adolescents. Regarding adult care, that network still prioritizes the psychiatric community-based care of people with SMI, with the aim to prevent relapses, avoid hospitalization and ensure the continuity of care $[5,31]$.

Over time, especially after their enactment, more MMHUs were established by General Hospitals and non-governmental organizations, both in the mainland and on the islands [5,32-36]. To date, about 25 units are in operation [37]. In addition, the services continue to evolve over the years and in 2018 a hybrid model of MMHU was launched, the Assertive Community Treatment model, which is addressed to patients who, due to the severity of their disease, are not committed to the already existing community services [38]. Alongside this, due to the recent migrant crisis of 2015, MMHUs are called to respond to the special mental needs of a great number of immigrants who arrived, and temporarily still reside, on Greek islands [35].

The positive contribution of MMHUs in the care of psychiatric patients has been reported over the years, both in Greece and abroad [7,32,36,39-44]. The effectiveness of the continuity of care for people with mental illness, the improvement of their functioning in the community, easy access to MHS without financial and distance restrictions, reduction in the frequency of relapses and the number of hospitalizations, addressing the needs of patients according to individualized approach, reduction of stigma and prejudice towards mental illness as well as its cost-effectiveness for the National Health System, patients and their families are some of the most important aspects of this contribution $[5,7,32,34,39,45]$. The prevention of relapses and hospitalization is considered of added value, since the more relapses of a patient, the more disabled they are likely to become [46-48], with all the negative consequences this entails for patients, their families/caregivers and society.

Funding: This research received no external funding.

Acknowledgments: The authors would like to thank Vaios Peritogiannis, M.D, for his comments on a previous version of the paper and Katerina Evangelou, Architect Engineer, for the graphic map's design.

Conflicts of Interest: The authors declare no conflict of interest.

\section{References}

1. Sakellaropoulos, P. Introduction. In Handbook of Adult Psychiatry-With Elements of Social Psychiatry and Its Applications in Greece; Lemperiere, T., Feline, A., Gutman, A., Ades, J., Pilate, C., Eds.; Papazisis Editions: Athens, Greece, 1995; pp. 27-48.

2. Peritogiannis, V.; Manthopoulou, T.; Gogou, A.; Mavreas, V. Mental Healthcare Delivery in Rural Greece: A 10-Year Account of a Mobile Mental Health Unit. J. Neurosci. Rural Pract. 2017, 8, 556-561. [CrossRef] [PubMed]

3. Ierodiakonou, C. A Mobile Unit in the Set up of a Rural Community Mental Health Centre: Experience and Results of the First Year of Function. Iatriki 44 1983, 225-232.

4. Law N. 2716, “Development and Modernization of Mental Health Services and Other Provisions". Official Government Gazette 96/A'17.5.1999. Available online: https:/ / www.elinyae.gr/ethniki-nomothesia/n-27161999-fek-96a-1751999 (accessed on 20 December 2021). 
5. Peritogiannis, V.; Rousoudi, S.; Vorvolakos, T.; Gioti, P.; Gogou, A.; Arre, A.; Samakouri, M. A Comparative Study of Two Mobile Mental Health Units in Different Catchment Rural Areas in Greece. Int. J. Soc. Psychiatry 2021, 002076402098589. [CrossRef] [PubMed]

6. Peritogiannis, V.; Mavreas, V. Community Mental Health Teams in Greece: The Paradigm of Mobile Mental Health Units. Arch Hell. Med. 2014, 31, 71-76.

7. Peritogiannis, V.; Mantas, C.; Alexiou, D.; Fotopoulou, V.; Mouka, V.; Hyphantis, T. The Contribution of a Mobile Mental Health Unit to the Promotion of Primary Mental Health in Rural Areas in Greece: A 2-Year Follow-Up. Eur. Psychiatry 2011, $26,425-427$. [CrossRef]

8. Fragkouli-Sakellaropoulou, A. The Mobile Mental Health Unit of the Prefecture of Fokida; Papazisis Editions: Athens, Greece, 2008.

9. Mavreas, V. Greece: The Transition to Community Care. Int. J. Soc. Psychiatry 1987, 33, 154-164. [CrossRef]

10. Sakellaropoulos, P.; Frangouli, A.; Panagoutsos, P.; Papadopoulos, P. Essai d' Organisation d' Un Dispositif de Psychiatrie Rurale En Grèce. Rev. Synap. 1986, 26, 48-54.

11. Madianos, M. Mental Illness and Mental Health Care in Greece. Public Health Rep. 1983, 11, 73-79.

12. Madianos, M. The Adventures of Psychiatric Reform in Greece: 1999-2019. BJPsych Int. 2020, 17, 26-28. [CrossRef]

13. Bouras, N.; Webb, Y.; Clifford, P.; Papadatos, Y.; Zouni, M. A Needs Survey among Patients in Leros Asylum. Br. J. Psychiatry 1992, 161, 75-79. [CrossRef]

14. Madianos, M.; Economou, M. Institutional Care Rehabilitation in Greece: A General View and the Case of Leros. In Psychiatry: A World Perspective; Elsevier: Amsterdam, The Netherlands, 1990; Volume 4, pp. 29-634.

15. Giannakopoulos, G.; Anagnostopoulos, D.C. Psychiatric Reform in Greece: An Overview. BJPsych Bull. 2016, 40, 326-328. [CrossRef] [PubMed]

16. Anagnostopoulos, D. Psychiatric Reform: Thoughts on Its Progress to Date. Athens Med. Assoc. Nerwsl. 2010, 215, 17-22.

17. Stefanis, C.N.; Madianos, M.G. Mental Health Care Delivery System in Greece: A Critical Overview. Bibl. Psychiatr. 1981, 160, 78-83.

18. Madianos, M.; Stefanis, C. Developmental Issues and Intervention Strategies in a Community Mental Health Centre in Greece. In Social Psychiatry; Hudolin, V., Ed.; Plenum: New York, NY, USA, 1984.

19. Stefanis, C.; Madianos, M.; Madianos, D.; Kounalaki, A. The First Community Mental Health Centre in Greece: Three Years Assessment of an Experiment. In Epidemiology and Community Psychiatry; Pichot, P., Berner, P., Wolf, R., Thau, K., Eds.; Springer: Boston, MA, USA, 1985.

20. Ierodiakonou, C.; Iacovides, A.; Bikos, C. Two Years of Implementation of a New Institution: Psychiatric Clinic in a General State Hospital. Brain 1982, 19, 197-382.

21. Bilanakis, N. Psychiatric Reform, an Effort That Began in 1982. In 1830-2020, History of Psychiatry in Modern Greece; BHTA: Athens, Greece, 2020; pp. 72-77, ISBN 978-960-452-303-0.

22. Frangouli, A. General Considerations on the Organization of Prevention. Application into the Province of Fokis. Tetramina 1984, $27,1737-1738$

23. Zikos, N. Organization of the Psychiatric Care Services in the Fokis Province. Tetramina 1984, 27, 1739-1749.

24. Panagoutsos, P. Structures Extrahospitalières Psychiatriques Aux Régions Rurales. Soins Des Psychoses Dans La Communauté. Ph.D. Thesis, Démocrite Université de Thrace, Komotini, Greece, 1994.

25. Zeikou, E.; Lazarstou, T.; Sakellaropoulos, P. Psychiatric Care in Patient's Home. In The Emotional Bond among Therapist and Patient, as the Foundation Stone of Psychiatry; Sakellaropoulos, P., Ed.; Papazisis Editions: Athens, Greece, 2010; pp. 627-641.

26. Ierodiakonou, C.; Iacovides, A.; Bikos, C. Mobile Mental Health Units associated with a general hospital in the province. Mater Med. Greca 1983, 11, 518-522.

27. Ierodiakonou, C.S. Psychotherapeutic Possibilities in a Rural Community Mental Health Center in Greece. Am. J. Psychother. 1983, 37, 544-551. [CrossRef] [PubMed]

28. Ierodiakonou, C.S. Experience of a Mobile Unit in a Greek Rural Community Mental Health Centre. In Epidemiology and Community Psychiatry; Pichot, P., Berner, P., Wolf, R., Thau, K., Eds.; Springer: Boston, MA, USA, 1985; pp. 379-384, ISBN 978-1-4684-4702-6.

29. Ierodiakonou, C.S.; Iacovides, A. Somatic Manifestations of Depressive Patients in Different Psychiatric Settings. Psychopathology 1987, 20, 136-143. [CrossRef]

30. Bouras, N. Mental Health Services in North-East Greece. Psychiatr. Bull. 1993, 17, 367-368. [CrossRef]

31. Livaditis, M. The influence of cultural factors on psychological and biological methods of treatment. In Culture $\mathcal{E}$ Psychiatry; Papazisis Editions: Athens, Greece, 2003; pp. 595-601, ISBN 978-960-02-1621-9.

32. Lykomitrou, A.; Stylianidis, S.; Geitona, M.; Pantelidou, S.; Souliotis, K. Assessment of the Mobile Mental Health Units' Effectiveness in Cyclades Islands. Psychiatriki 2021, 32, 199-207. [CrossRef]

33. Dimopoulou, M.; Fanti, R.M.; Kiourktsi, V.; Louvros, K.; Zennetou, I.; Kavvadia, A.; Alamantos, I. Psychosocial Intervention in Primary Health Care. The Development of the Mobile Mental Health Unit of Corfu/Lefkada. Med. Ann. Northwest Greece 2011, 8, $44-48$.

34. Garbi, A.; Tiniakos, I.; Mikelatou, Z.; Drakatos, I. Decrease of Hospitalizations and Length of Hospital Stay in Patients with Schizophrenia Spectrum Disorders or Bipolar Disorder Treated in a Mobile Mental Health Service in Insular Greece. Psych 2021, 3 , 780-791. [CrossRef] 
35. Fylla, I.; Fousfouka, E.; Kostoula, M.; Giannakopoulou, K.; Spentzouri, P. The Interventions of a MMHU on the Refugee Crisis on a Greek Island. Psych 2022, 4, 49-59. [CrossRef]

36. Pantelidou, S.; Manolesou, S.; Apostolopoulou, A.; Giannakopoulou, K.; Stylianidis, S. Albanian Migrants in Cyclades: Contact with Mental Health Services and Implications for Practice. Psych 2021, 3, 916-930. [CrossRef]

37. Ministry of Health-Mental Health Directorate Sectoral Planning for the Development of Mental Health Units. 2019. Available online: https: / / www.moh.gov.gr/articles/health/domes-kai-draseis-gia-thn-ygeia/c312-psyxikh-ygeia/monades-psyxikhsygeias/5520-ekthesh-sxediasmos-anaptykshs-monadwn-psyxargws (accessed on 20 December 2021).

38. Peritogiannis, V.; Tsoli, F. The Greek Hybrid Version of the Assertive Community Treatment Model: A Perspective View between Challenges and Limitations. Psych 2021, 3, 792-799. [CrossRef]

39. Peritogiannis, V.; Tatsioni, A.; Menti, N.; Grammeniati, A.; Fotopoulou, V.; Mavreas, V. Treatment Engagement of Psychotic Patients with a Mobile Mental Health Unit in Rural Areas in Greece: A Five-Year Study. Schizophr. Res. Treat. 2013, 2013, 613956. [CrossRef]

40. Bonsack, C.; Holzer, L.; Stancu, I.; Baier, V.; Samitca, M.; Charbon, Y.; Koch, N. Psychiatric Mobile Teams for the Three Ages of Live: The Lausanne Experience. Rev. Médicale Suisse 2008, 4, 1960-1969.

41. Turner, T. The History of Deinstitutionalization and Reinstitutionalization. Psychiatry 2004, 3, 1-4. [CrossRef]

42. Thornicroft, G.; Deb, T.; Henderson, C. Community Mental Health Care Worldwide: Current Status and Further Developments. World Psychiatry 2016, 15, 276-286. [CrossRef] [PubMed]

43. Cervello, S.; Pulcini, M.; Massoubre, C.; Trombert-Paviot, B.; Fakra, E. Do Home-Based Psychiatric Services for Patients in Medico-Social Institutions Reduce Hospitalizations? Pre-Post Evaluation of a French Psychiatric Mobile Team. Psychiatr. Q. 2019, 90, 89-100. [CrossRef]

44. Phillips, S.D.; Burns, B.J.; Edgar, E.R.; Mueser, K.T.; Linkins, K.W.; Rosenheck, R.A.; Drake, R.E.; McDonel Herr, E.C. Moving Assertive Community Treatment into Standard Practice. Psychiatr. Serv. 2001, 52, 771-779. [CrossRef] [PubMed]

45. Peritogiannis, V.; Nikolaou, P. Functioning in Community-Dwelling Patients with Schizophrenia Spectrum Disorders in Rural Greece. Int. J. Soc. Psychiatry 2020, 66, 111-117. [CrossRef] [PubMed]

46. López-Jaramillo, C.; Lopera-Vásquez, J.; Gallo, A.; Ospina-Duque, J.; Bell, V.; Torrent, C.; Martínez-Arán, A.; Vieta, E. Effects of Recurrence on the Cognitive Performance of Patients with Bipolar I Disorder: Implications for Relapse Prevention and Treatment Adherence: Cognitive Effects of Recurrence in BD-I. Bipolar Disord. 2010, 12, 557-567. [CrossRef] [PubMed]

47. Balogh, N.; Égerházi, A.; Berecz, R. Neurocognitive Changes in Patients with Schizophrenia during Relapse and Early Remission. Eur. J. Psychiatry 2015, 29, 199-209. [CrossRef]

48. Nasrallah, H.A. 10 Devastating Consequences of Psychotic Relapses. Curr. Psychiatry 2021, 20, 9-12. [CrossRef] 